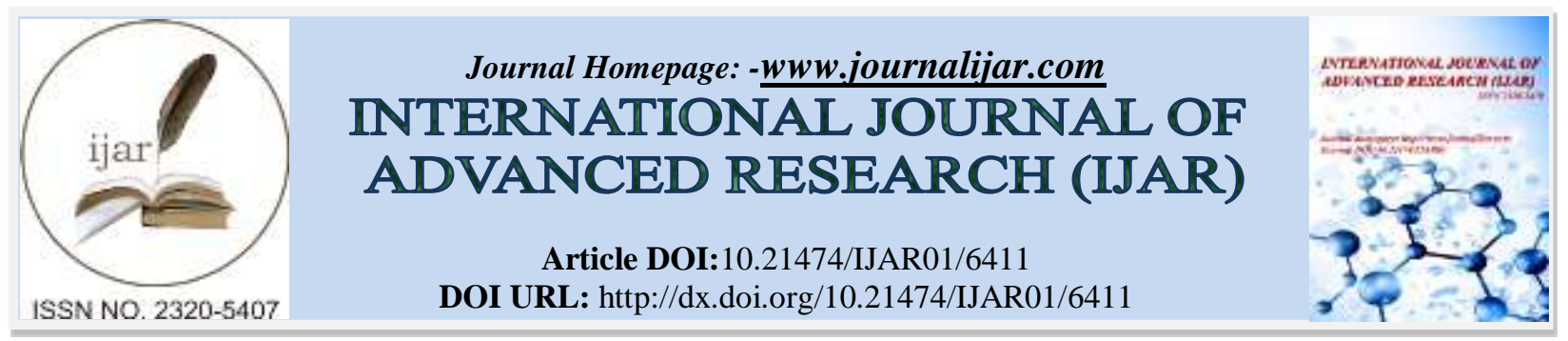

RESEARCH ARTICLE

\title{
HEMATOCOLPOS CAUSING URINARY RETENTION IN 10 YEARS OLD. UNCOMMON PRESENTATION.
}

\author{
Mohamed alaqqad ${ }^{1}$, Ammar Hashash ${ }^{1}$, Packirisamy Kannan ${ }^{1}$, Mehvish Nazir ${ }^{1}$, Ammar MH Shehadeh $^{2}$, \\ Ebtessam Elsayed ${ }^{3}$ and Issam Merghani ${ }^{4}$. \\ 1. General Surgery Department, Hatta Hospital, Dubai, United Arab Emirates. \\ 2. Pediatric Department, Hatta Hospital, Dubai, United Arab Emirates. \\ 3. Obstetrics \& Gynecology Department, Hatta Hospital, Dubai, United Arab Emirates. \\ 4. Family medicine Department, Hatta hospital, United Arab Emirates.
}

\section{Manuscript Info}

\section{Manuscript History}

Received: 01 December 2017

Final Accepted: 03 January 2018

Published: February 2018

\begin{abstract}
Urine retention in pediatric is rare. Usually is associated with stone impacted in urethra or congenital anomalies. We report in this case, 10 years old child presented with acute urinary retention. During the management of her urine retention by inserting Foleys catheter, we observed the bulging hymen, so we went for further investigation to role the underlying cause of retention. The ultrasound confirmed the diagnosis of hematolcolpos, which we treated with cruciate incision.
\end{abstract}

Copy Right, IJAR, 2018,. All rights reserved.

\section{Introduction:-}

Hematocolpos is a medical condition in which the vagina fills with menstrual blood. It is often caused by the combination of menstruation with an imperforate hymen ${ }^{(1,2)}$.

Inspection of the external genitalia and anus are important components of the physical examination of the female neonate and child. Imperforate hymen has been diagnosed with prenatal ultrasound documentation of bladder outlet obstruction due to hydrocolpos or mucocolpos. However, in spite of the recommendations for inspection of the external genitalia during the neonatal and early childhood period, variations in hymenal anatomy commonly escape diagnosis until the time of menarche. Anatomic anomalies that can be confused with imperforate hymen in the differential diagnosis should be considered ${ }^{(3,4)}$.

Imperforate hymen is uncommon, occurring in $0.1 \%$ of newborn females. Non-syndromic familial occurrence of imperforate hymen is extremely rare and has been reported only three times in the English literature ${ }^{(5)}$.

Imperforate hymen and related genital tract anomalies result from abnormal or incomplete embryologic development.

The differential diagnosis is including Labial adhesions, incomplete hymenal obstruction, hymenal bands, Obstructing longitudinal or transverse septa, vaginal agenesis or androgen insensitivity. Acute urinary retention is a very rare presentation of hematocolpos with less than 10 reported cases in literature ${ }^{(5,6,7,8)}$ 


\section{Case report:-}

10 years adolescence presented to our emergency department with acute urinary retention, with developed gender and without menarche. During the insertion of the Foley's catheter, we observed the bulging imperforate hymen. After evacuating the bladder, she was scanned with sonography and CT scan. The scanning showed large fluid-fluid accumulation within the vagina with consequent bladder distention due to outlet obstruction, most probably due to imperforate hymen.

Then the patient endorsed to the gynecologist for surgical management in the second day. The patient was managed with cruciate incision.

The urine catheter was removed post operatively and discharged on good health.

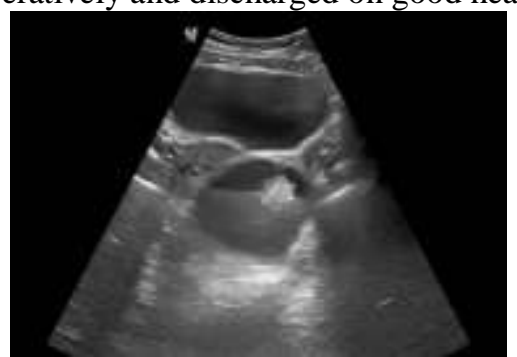

Figure 1:- the ultrasound is showing large fluid-fluid accumulation within the vagina with consequent bladder distention due to outlet obstruction.

\section{Discussion:-}

Hematocolpos causing acute urinary retention is a rare presentation. In this case it was due to imperforated hymen. As mentioned before it could be to congenital anomalies. The cases which reported similar to this case are rare ${ }^{(5,6,7)}$. The only management of this problem is surgical. Usually it is detected in adolescent girls, when they heavy cyclic pelvic pain, back pain, amenorrhea with acute urinary retention. Even they present with diarrhea.

Symptoms can be relived with combined contraceptive pills and NSAIDs. The surgical management is hymenotomy. The most common surgical technique used is hymenotomy, which can be done in circular, cruciate or even vertical incision.

The clinical assessment is the base line for diagnosis of hematocolpos, with the help of sonography to scan the internal genital organs and urinary tract.

The case which we report her, is similar to case which reported in the literature like Anselm et al, ${ }^{(6)}$. The difference from other cases is that there are congenital anomalies like McKusick-Kaufman syndrome or hymenal atresia and like in our case imperforate hymen ${ }^{(10)}$. A series of 13 cases showed 4 cases presented with acute urinary retention due to imperforated hymen, while the rest presented with pelvic pain ${ }^{(11)}$.

Her history and clinical examination was quite enough to diagnose the urinary retention due the hematocolpos, but the sonography has role to detect the effect of the back pressure over the kidney and to confirm the hematocolpos or hematometra. This scenario of presentation can be discovered at neonatal period through proper examination of the genitalia. The undiscovered and untreated hematocolpos caused her acute urinary retention, which should be preventable. This girl was non-citizen patient who is coming grown up in poor country, where the health service is not matching the standard concepts.

\section{Conclusion:-}

Acute urinary retention due to imperforate hymen in adolescence is rare condition. The management depend on the underlying cause, upon careful assessment and diagnosis at neonatal period. Ultrasound is a useful tool to confirm the diagnosis and to check the urinary system. 


\section{References:-}

1. Kloss, Brian T, Nacca, Nicholas E.; Cantor, Richard M. "Hematocolpos secondary to imperforate hymen". International Journal of Emergency Medicine 3 (4): 481-482. doi:10.1007/s12245-010-0171-2. PMC 3047835. PMID 21373333.

2. Tompkins, Pendleton ."The Treatment of Imperforate Hymen with Hematocolpos". Journal of the American Medical Association 113 (10): 913-916. doi:10.1001/jama.1939.02800350023007.

3. Braverman PK, Breech L. American Academy of Pediatrics. "Clinical report--gynecologic examination for adolescents in the pediatric office setting". Pediatrics. 2010 Sep. 126(3):583-90. [Medline].

4. Parazzini F, Cecchetti G. "The frequency of imperforate hymen in northern Italy". Int J Epidemiol. 1990 Sep. 19(3):763-4. [Medline].

5. Sakalkale R, Samarakkody U. "Familial occurrence of imperforate hymen". J Pediatr Adolesc Gynecol. 2005 Dec. 18(6):427-9. [Medline].

6. O.O. Anselm, U.H. Ezegwui. "Imperforated hymen presenting as acute urinary retention in a 14-year-old Nigerian girl" J Surg Tech Case Rep, 2 (2010), pp. 84-.

7. C.M. Giaccio, M.G. Epstein, E.E. Calore, C.A. de Moura, C.N. Tavares "Imperforate hymen in a 13-year-old adolescent Einstein". 5 (2007), pp. 392-393.

8. J.W. Chang, L.Y. Yang, H.H. Wang, J.K. Wang, C.M. Tiu "Acute urinary retention as the presentation of imperforated hymen" J Chin Med Assoc, 70 (2007), pp. 559-561

9. Lacy, Judith. "Imperforate hymen". The 5-minute Obstetrics and Gynecology Consult. Lippincott Williams \& Wilkins. pp. 116-117. ISBN 9780781769426.

10. Kloss, Brian T, Nacca, Nicholas E, Cantor, Richard M. "Hematocolpos secondary to imperforate hymen". International Journal of Emergency Medicine 3 (4): 481-482. doi:10.1007/s12245-010-0171-2. PMC 3047835. PMID 21373333.

11. Unbound Medline. http://www.unboundmedicine.com/medline/citation/20415189/[Imperforate_hymen:_a_series_of_13_cases]. 